Contents lists available at Journal IICET

International Journal of Technology, Innovation and

Humanities

IICET

ISSN: 2746-6434

Journal homepage: http://journal.iicet.org/index.php/ijtih

\title{
The relationship of concentration and eye-hand coordination with accuracy of backhand backspin serve in table tennis
}

\author{
Jeki Haryanto ${ }^{\left.1^{*}\right)}$, Frizki Amra ${ }^{1}$ \\ ${ }^{1}$ Faculty of Sports Science, Universitas Negeri Padang, Indonesia
}

\begin{tabular}{l} 
Article Info \\
Article history: \\
Received Aug $30^{\text {th }}, 2020$ \\
Revised Sep $29^{\text {th }}, 2020$ \\
Accepted Oct $28^{\text {th }}, 2020$ \\
\hline
\end{tabular}

\section{Keyword:}

Concentration

Eye-hand coordination

Service accuracy

Table tennis

\begin{abstract}
The purpose of this study was to analyze the relationship between concentration and hand eye coordination with the accuracy of backhand backspin service. Quantitative approaches and correlational methods are used in this study. This research was conducted at PTM Gempas. The population in this study were all cadet athletes at PTM Gempas, while the sampling technique used was saturated sampling, which means that all athletes totaling 20 people were used as samples. Player concentration data is collected using a concentration grid test, hand eye coordination data is obtained by throwing a tennis ball test, and data for backhand backspin service accuracy is obtained by testing servicing. The results of this study are as follows: 1) Concentration has a strong enough relationship with the accuracy of backhand backspin service, 2) Hand eye coordination has a strong enough relationship with backhand backspin service accuracy. 3) Concentration and hand eye coordination together have a strong enough relationship with backhand backspin service accuracy. Table tennis coach should train the concentration and eye-hand coordination to improve the athlete's service accuracy.
\end{abstract}

(C) 2020 The Authors. Published by Redwhitepress.

This is an open access article under the CC BY-NC-SA license

(https://creativecommons.org/licenses/by-nc-sa/4.0/

\section{Corresponding Author:}

Jeki Haryanto,

Universitas Negeri Padang

Email: jekiharyanto@fik.unp.ac.id

\section{Introduction}

Service is the main capital for a player to get points, the large variety of services a player has will make it difficult for the opponent to anticipate what service will be served, service that cannot be anticipated properly by the opponent will be an advantage for the service provider, the ball returned is usually becomes easy to turn off (Norzuria Ibrahim, et al., 2020; Li \& Yang, 2020). Conversely, an inaccurate service will make it easier for the recipient to attack earlier after the service is provided. Servicing plays an important role in winning the match, good serve, attacking the ball that is taken directly after serving, or attacking the ball after receiving service with forehand and backhand will determine who will be the winner in a match (Chen \& Huang, 2020; C.-Y. Sung, 2019).

The placement of the ball when service is very important if you want to win in a match. In addition to the placement of the ball, the factor of the type of ball spin given will also increase the difficulty for the service recipient (N. Ibrahim, et al., 2020). If a player is able to provide the right service according to the tactics he is playing and the ball spin is difficult to predict, then there is a big possibility that the ball he will receive after 
service can be attacked easily, therefore players must hone their skills in performing various services if they want to win. a match (Sun, Luo, \& Zhao, 2020; Jiachen Wang, et al., 2019).

There are many variations in table tennis services and one of them is the backhand backspin service (Bań kosz \& Winiarski, 2020). This service can produce both slow and fast ball speeds. In addition, when viewed in terms of placement, this service can be placed near the net (short serve) or it can also be placed at the back end of the table away from the net (long serve) (Yu, Shao, \& Gu, 2019). This type of service is usually used to keep the ball in a low position so that it is difficult to immediately attack by an opponent. The inability of the opponent to return the backspin service can also be used to find points that ended in victory for the service provider (Inaba, et al., 2017; Sari, 2020).

Several previous studies have attempted to look at the problem of service accuracy performed by table tennis players (Nabil, et al., 2020). There are many factors that affect serive accuracy, wrist flexibility is one of the factors that can increase service accuracy when playing table tennis. A research result shows that the more flexible the wrists, the easier it is for players to position the ball in the area where they are playing. Difficult ball positions and strong ball spin due to wrist flexibility will certainly benefit the server, so the possibility of making more points is possible (C. Y. Sung, 2019; Z. Zhou \& Zhang, 2020)

A research to improve service skills in table tennis has also been carried out (Yu, et al., 2019). Improving service skills for students of class V Elementary School can be done by means of reciprocal teaching styles, meaning that giving instructions to students, both those who act as service actors and those who act as observers, are carried out at the beginning of the lesson so that in the absence of very detailed instructions from the teacher it provokes creativity learners to practice various things related to the material about the service he is learning (Y. Zhou, 2018). Giving feedback from students who act as observers greatly helps students who act as service actors so that this has an impact on increasing their service learning outcomes (Galvan, Meaney, \& Gray, 2018). In other studies, improving service skills was carried out using walls as a training aid. Limitations of tables and limited space to practice make learning outcomes less optimal (Faber, Elferink-Gemser, Oosterveld, Twisk, \& Nijhuis-Van der Sanden, 2017; J. Wang, 2019). A classroom action research study shows that utilizing wall media to train third semester students who are taking table tennis courses shows an increase in service skills after being directed to use the wall as a friend for practice (Ren, Huang, Guo, Wu, \& Sun, 2019)

(Angraini, 2020) recommends further research to see how much concentration contributes to directing serve for a table tennis player. Seeing the importance of service accuracy in the game of table tennis and the lack of research results that can explain the role of concentration and eye-hand coordination on backhand backspin service accuracy, this research is very relevant to do. This study aims to analyze how the form of the relationship between concentration and eye-hand coordination with the accuracy of backhand backspin service in table tennis.

\section{Method}

This study uses a quantitative approach and correlational methods (Tenenbaum \& Driscoll, 2005) . Researchers wanted to analyze how much the relationship between concentration and eye-hand coordination of table tennis athletes at PTM (Persatuan Tenis Meja/ Tabel Tennis Association) Gempas on service accuracy.This research conducted on Sunday, October 11, 2020, located at PTM (Persatuan Tenis Meja) Gempas Pauh Sicincin. Padang Pariaman Regency, West Sumatra Province, Indonesia.The population in this study were all table tennis cadet athletes at PTM Gempas, while the sample was all table tennis cadet athletes at PTM Gempas, this was due to the small number of population so that the sampling technique was census sampling.

To find out how the concentration level of table tennis cadet athletes at PTM Gempas, researchers used the concentration grid test from Haris and Bette L. Harris (Greenlees, Thelwell, \& Holder, 2006). This test has $10 \times 10$ squares, each of which contains two digit numbers ranging from 00 to 99 . The sample is asked to connect the numbers sequentially from the numbers 00 to 99 either vertically or horizontally for 1 minute.To measure the eye-hand coordination, the researchers chose the eye-hand coordination test by throwing a tennis ball on the target wall. To score one point: the ball must be thrown from below, the ball must hit the target, the ball must be immediately caught by the hand without a previous obstacle, the testi does not move or move outside the boundary line to catch the ball. Add the results of the first 10 and 10 tosses.

Testi stood behind the table opposite the part of the table that had been assigned the boundaries of the target area. While holding the bet and the ball then testi performs a service directed towards the target that has 
been given a score. Testi is given the opportunity to service 10 times. The valid service is in accordance with the service rules in the game.

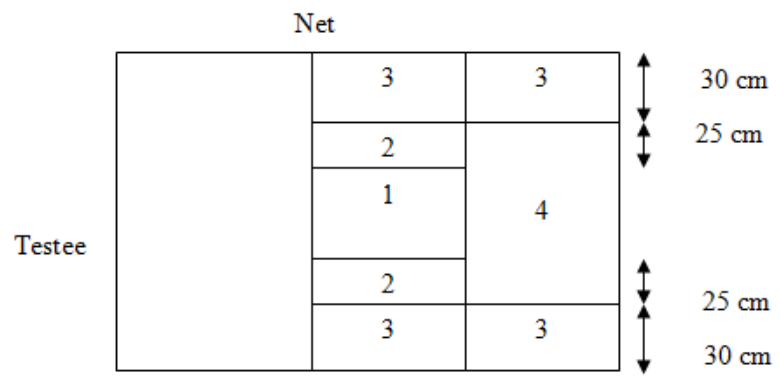

Figure 1. The Service rules

After all the data has been collected, the normality test is carried out as a prerequisite test for parametric statistics. The normality test is done by using the Liliefors test. Then proceed with the Pearson product moment correlation test and multiple correlation test.

\section{Results and Discussions}

\section{Test the analysis requirements}

Before the data is processed using the Pearson Product Moment correlation, first see whether the data is normally distributed or not. To determine the normality of the data on the three variables in this study, the Liliefors test was used. The results of the Liliefors test can be seen in the following table:

Tabel 1. Data normality tests of research variabels

\begin{tabular}{rlccc}
\hline No & Variable & LO & Ltabel & Information \\
\hline $\mathbf{1}$ & Concentration & 0.172 & 0.190 & Normal \\
$\mathbf{2}$ & Eye-hand coordination & 0.166 & 0.190 & Normal \\
$\mathbf{3}$ & Backspin backhand serve accuracy & 0.114 & 0.190 & Normal \\
\hline
\end{tabular}

Based on the results of the data normality test of the three research variables, it can be concluded that all research variables are normally distributed so that they can meet the requirements for the Pearson product moment analysis.

\section{Concentration relationship with backhand backspin service accuracy}

Based on the data analysis conducted with the Pearson product moment correlation, the level of relationship between concentration and accuracy of backhand backspin service is 0.44 , which means that the level of relationship between the two variables is in the sufficient category.

In sports, the concentration factor often does not get serious attention by the coach, even though the role of concentration is very important in all sports, including table tennis (Bastug, 2018; Van Biesen, et al., 2010). The coach gives too much physical exercise even though he should train the concentration of the players to be included in his training program. The many distractions that players will receive when competing must be able to be overcome if you want to win the match. Concentration that is distracted by the noise made by the audience should not be used as an excuse by a professional player. Because this concentration is very important, the coach should also provide forms of concentration training for the players who will compete so that the players feel ready both physically and psychologically (Ericsson, 2020; Komarudin \& Mulyana, 2017). The results of other studies indicate that positive emotions possessed by an athlete will increase the athlete's concentration and performance. Concentration and good performance are of course really needed in a match situation, especially when it comes to serving (Vast, Young, \& Thomas, 2010).

Accurate service in the game of table tennis is closely related to the concentration of the person who does it (Rahmadiky, 2020; Van Biesen, et al., 2010). The positive correlation that occurs between these two variables must receive attention from both the coach and the athlete himself. In addition, eye-hand coordination is also a variable that cannot be ignored to support the accuracy of backhand backspin service so it must also be trained seriously and continuously. The results showed that the concentration contributed $68.9 \%$ to the level of service accuracy (Aditya Tantra, 2016). 
Eye-hand coordination relationship with backhand backspin service accuracy

Based on data analysis carried out with Pearson product moment correlation, the correlation level between eye-hand coordination and backhand backspin service accuracy is 0.48 , which means that the level of relationship between the two variables is in the sufficient category.

The results showed that the strength of the relationship between eye-hand coordination and accuracy of backhand backspin service was quite strong. This indicates that to perform accurate service is not absolutely influenced by the eye-hand coordination possessed by the athlete. On the other hand, without good eye-hand coordination, accurate service will be difficult to obtain. This is in line with a study which showed that the contribution of eye-hand coordination to service accuracy only contributed $25.3 \%$ (Andria \& Igoresky, 2020). The accuracy of the strokes and the success of the athletes in the future can be seen from the high level of eyehand coordination of athletes now (Laby, Kirschen, Govindarajulu, \& DeLand, 2018).

Hand-eye coordination is a component of the physical condition that is needed in table tennis. The many types of balls that come from the opponent coupled with the fast rate of speed make a player must be able to coordinate his eyes and hands to hit the ball precisely. Even when serving a player, a player must also be able to coordinate his eyes and hands so that the contact between the bed and the ball has the right timing, so that the ball's rotation, ball speed, and placement can be carried out correctly (Paul, Biswas, \& Sandhu, 2011). A study explains that the speed of eye-hand coordination cannot be done perfectly if the athlete experiences an injury to the neck, without eye movement assisted by agile neck rotation, good eye-hand coordination cannot be obtained so that the athlete will also have difficulty serving (Mutasim, Stuerzlinger, \& Batmaz, 2020; Przednowek, et al., 2019)

The relationship between concentration and eye-hand coordination with the accuracy of backhand backspin service

Based on data analysis conducted with Pearson product moment correlation, the level of relationship between concentration and eye-hand coordination with backhand backspin service accuracy is 0.55 , which means that the level of relationship between the two variables is in the sufficient category.

Service accuracy is often the determinant of victory in a match. When the crucial points are that the athlete should not make mistakes and the athlete makes mistakes, it will clearly have an impact on defeat. Therefore how the role of concentration when athletes perform services must be known, as well as the contribution of eye-hand coordination, which plays a very important role in providing service, must also be known by both the athlete and the coach himself, this is useful for considering the development of a training program so that accuracy service becomes more accurate and consistent (Mutasim, et al., 2020; Przednowek, et al., 2019). Feelings of bad performance in competition are more often found in female athletes and athletes who are old (Grossbard, Smith, Smoll, \& Cumming, 2009). The frustration that occurs in a match situation will also reduce concentration which will lead to a series of errors and confusion in the athlete which will obviously have an impact on the inaccuracy of one of the services (McCarthy, Allen, \& Jones, 2013). On the other hand, the feeling of pleasure and the absence of pressure that is felt when playing will increase concentration in directing the service (Allen, Jones, McCarthy, Sheehan-Mansfield, \& Sheffield, 2013).

If a player already has good eye-hand coordination, a good service practice is one where the direction of the service target varies, in contrast to a player who has not been trained in hand-eye coordination, then the service direction must be fixed first. With the coach's attention regarding the suitability of the form of training in accordance with the level of coordination of the players, the ability of the player's service level accuracy will quickly develop (Andria \& Igoresky, 2020; Basiri, Farsi, Abdoli, \& Kavyani, 2020).

\section{Conclusions}

Based on The results of this study can be conclude that Concentration has a strong enough relationship with the accuracy of backhand backspin service. Hand eye coordination has a strong enough relationship with backhand backspin service accuracy. Concentration and hand eye coordination together have a strong enough relationship with backhand backspin service accuracy. Table tennis coach should train the concentration and eye-hand coordination to improve the athlete's service accuracy. Training in concentration and eye-hand coordination should not be overlooked by the coach, because it also contributes to the accuracy of service that is so needed by athletes to win competitions. 


\section{References}

Aditya Tantra, F. (2016). Kontribusi Konsentrasi Dan Kelentukan Pergelangan Tangan Terhadap Ketepatan Short Serve Pada Pemain Bulutangkis Sman 2 Tanggul Jember. Jurnal Kesehatan Olahraga, 4(4).

Allen, M. S., Jones, M., McCarthy, P. J., Sheehan-Mansfield, S., \& Sheffield, D. (2013). Emotions correlate with perceived mental effort and concentration disruption in adult sport performers. European Journal of Sport Science, 13(6), 697-706.

Andria, Y., \& Igoresky, A. (2020). The Contribution of Grip Strength and Eye-Hand Coordination Towards Service Accuracy in Tennis Athletes. Jipes-Journal Of Indonesian Physical Education and Sport, 6(01), 17-22.

Angraini, J., Ridwan, M., Fardi, A., \& Haryanto, J. (2020). Sport Science: Journal of Sports Science and Physical Education. In Sport Science, 20(2).

Bań kosz, Z., \& Winiarski, S. (2020). Statistical Parametric Mapping Reveals Subtle Gender Differences in Angular Movements in Table Tennis Topspin Backhand. International journal of environmental research and public health, 17(19), 6996.

Basiri, F., Farsi, A., Abdoli, B., \& Kavyani, M. (2020). The Effect of Visual and Tennis Training on Perceptual-Motor Skill and Learning of Forehand Drive in Table Tennis Players. Journal of Modern Rehabilitation, 14(1), 21-32.

Bastug, G. (2018). Investigation of attention, concentration and mental toughness properties in tennis, table tennis, and badminton athletes. The Sport Journal, 21.

Chen, Y.-F., \& Huang, C.-C. (2020). Performance Effects of Different Table Tennis Ball Materials. Smart Science, 8(2), 84-94.

Ericsson, K. A. (2020). Towards a science of the acquisition of expert performance in sports: Clarifying the differences between deliberate practice and other types of practice. Journal of Sports Sciences, 38(2), 159176.

Faber, I. R., Elferink-Gemser, M. T., Oosterveld, F. G. J., Twisk, J. W. R., \& Nijhuis-Van der Sanden, M. W. G. (2017). Can an early perceptuo-motor skills assessment predict future performance in youth table tennis players? An observational study (1998-2013). [Article]. Journal of Sports Sciences, 35(6), 593-601.

Galvan, C., Meaney, K., \& Gray, V. (2018). Examining the reciprocal nature of service-learning for underserved students and preservice teachers. Journal of Teaching in Physical Education, 37(4), 363-372.

Greenlees, I., Thelwell, R., \& Holder, T. (2006). Examining the efficacy of the concentration grid exercise as a concentration enhancement exercise. Psychology of sport and exercise, 7(1), 29-39.

Grossbard, J. R., Smith, R. E., Smoll, F. L., \& Cumming, S. P. (2009). Competitive anxiety in young athletes: Differentiating somatic anxiety, worry, and concentration disruption. Anxiety, Stress, \& Coping, 22(2), 153-166.

Ibrahim, N., Abu Osman, N. A., Mokhtar, A. H., Arifin, N., Usman, J., \& Shasmin, H. N. (2020). Contribution of the arm segment rotations towards the horizontal ball and racket head velocities during forehand long shot and drop shot services in table tennis. [Article]. Sports Biomechanics.

Ibrahim, N., Abu Osman, N. A., Mokhtar, A. H., Arifin, N., Usman, J., \& Shasmin, H. N. (2020). Contribution of the arm segment rotations towards the horizontal ball and racket head velocities during forehand long shot and drop shot services in table tennis. Sports Biomechanics, 1-17.

Inaba, Y., Tamaki, S., Ikebukuro, H., Yamada, K., Ozaki, H., \& Yoshida, K. (2017). Effect of changing table tennis ball material from celluloid to plastic on the post-collision ball trajectory. [Article]. Journal of Human Kinetics, 55(1), 29-38.

Komarudin, \& Mulyana. (2017). The Effect of Brain Jogging Exercise Toward the Increase of Concentration and Learning Achievement. Paper presented at the IOP Conference Series: Materials Science and Engineering.

Laby, D. M., Kirschen, D. G., Govindarajulu, U., \& DeLand, P. (2018). The hand-eye coordination of professional baseball players: The relationship to batting. Optometry and Vision Science, 95(7), 557-567.

Li, F., \& Yang, X. (2020). Correction Simulation of Three Dimensional Image of Table Tennis Players Serve Position. Paper presented at the ACM International Conference Proceeding Series.

McCarthy, P. J., Allen, M. S., \& Jones, M. V. (2013). Emotions, cognitive interference, and concentration disruption in youth sport. Journal of Sports Sciences, 31(5), 505-515.

Mutasim, A. K., Stuerzlinger, W., \& Batmaz, A. U. (2020). Gaze tracking for eye-hand coordination training systems in virtual reality. Paper presented at the Conference on Human Factors in Computing Systems Proceedings.

Nabil, A., Hegazy, H., Abdelsalam, M., Hussien, M., Elmosalamy, S., Hassan, Y. M., et al. (2020). Usability Study of a comprehensive table tennis AR-based training system with the focus on players' strokes. Journal of Ubiquitous Systems \& Pervasive Networks, 13(1), 01-09. 
Paul, M., Biswas, S. K., \& Sandhu, J. S. (2011). Role of sports vision and eye hand coordination training in performance of table tennis players. Brazilian Journal of Biomotricity, 5(2), 106-116.

Przednowek, K., Śliz, M., Lenik, J., Dziadek, B., Cieszkowski, S., Lenik, P., et al. (2019). Psychomotor abilities of professional handball players. [Article]. International journal of environmental research and public health, 16(11).

Rahmadiky, I. (2020). The Contribution of Hand-Eye Coordination and Arm Muscle Strength on Punch Ability of Forehand Drive of Table Tennis Athletes. Paper presented at the 1st International Conference of Physical Education (ICPE 2019).

Ren, Y., Huang, Z., Guo, Y., Wu, J., \& Sun, Y. (2019). Kinematic characteristics of backhand block in table tennis. Paper presented at the ACM International Conference Proceeding Series.

Sari, D. N. (2020). The Effect of Discovery Teaching Style on Basic Techniques of Table Tennis Skills at SMP Semen Padang. Paper presented at the 1st Progress in Social Science, Humanities and Education Research Symposium (PSSHERS 2019).

Sun, J., Luo, H., \& Zhao, H. (2020). Research on Automatic Generation of Table Tennis Technique and Tactics Collection Template. International Journal of Machine Learning and Computing, 10(1).

Sung, C.-Y. (2019). A Smart Analysis of Technical Skills of Top Male Table Tennis Players. Smart Science, $7(4), 231-238$.

Sung, C. Y. (2019). A Smart Analysis of Technical Skills of Top Male Table Tennis Players. [Article]. Smart Science, 7(4), 231-238.

Tenenbaum, G., \& Driscoll, M. P. (2005). Methods of research in sport sciences: Quantitative and qualitative approaches: Meyer \& Meyer Verlag.

Van Biesen, D., Verellen, J., Meyer, C., Mactavish, J., Van de Vliet, P., \& Vanlandewijck, Y. (2010). The ability of elite table tennis players with intellectual disabilities to adapt their service/return. Adapted physical activity quarterly, 27(3), 242-257.

Vast, R. L., Young, R. L., \& Thomas, P. R. (2010). Emotions in sport: Perceived effects on attention, concentration, and performance. Australian Psychologist, 45(2), 132-140.

Wang, J. (2019). Comparison of table tennis serve and return characteristics in the London and the Rio Olympics. [Article]. International Journal of Performance Analysis in Sport, 19(5), 683-697.

Wang, J., Zhao, K., Deng, D., Cao, A., Xie, X., Zhou, Z., et al. (2019). Tac-Simur: Tactic-based simulative visual analytics of table tennis. IEEE transactions on visualization and computer graphics, 26(1), 407417.

Yu, C., Shao, S., \& Gu, Y. (2019). The analysis of foot loadings in high-level table tennis athletes during short topspin ball between forehand and backhand serve. [Article]. International Journal of Biomedical Engineering and Technology, 31(4), 375-387.

Zhou, Y. (2018). Neu-efficiency of table tennis player in the cognitive task with central resource consumption. [Article]. NeuroQuantology, 16(6), 446-450.

Zhou, Z., \& Zhang, H. (2020) A multi-dimensional analytical system of table tennis matches. Vol. 1028 AISC. Advances in Intelligent Systems and Computing (pp. 45-52). 